\title{
Selective cyclooxygenase 2 inhibitor induces indefinite survival of fully allogeneic cardiac grafts and generates $\mathrm{CD}^{+}$regulatory cells
}

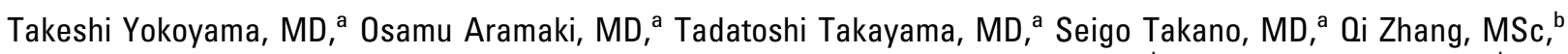
Motohide Shimazu, MD, ${ }^{\mathrm{c}}$ Masaki Kitajima, MD, FACS, ${ }^{\mathrm{c}}$ Yoshifumi Ikeda, MD, FACS, ${ }^{\mathrm{b}}$ Nozomu Shirasugi, MD, ${ }^{\mathrm{b}}$ and Masanori Niimi, MD, PhD, FACS

From the Departments of Surgery of Nihon University School of Medicine, Teikyo University, and Keio University School of Medicine, Tokyo, Japan.

Received for publication Jan 17, 2005; revisions received May 15, 2005; accepted for publication June 20, 2005 .

Address for reprints: Nozomu Shirasugi, MD, Department of Surgery, Teikyo University, 2-11-1 Kaga, Itabashi-ku, Tokyo 173-8605, Japan (E-mail: nozomujs@med.teikyo-u. ac.jp)

J Thorac Cardiovasc Surg 2005;130:1167-74 $0022-5223 / \$ 30.00$

Copyright () 2005 by The American Association for Thoracic Surgery

doi:10.1016/j.jtcvs.2005.06.031
Background: Selective inhibition of cyclooxygenase 2 has been reported to have not only anti-inflammatory effects but also effects on the immune response. We investigated ability of a cyclooxygenase 2 inhibitor to inhibit alloimmune response in a murine cardiac transplantation model.

Methods: $\mathrm{CBA}\left(\mathrm{H} 2^{\mathrm{k}}\right)$ mice underwent transplantation of $\mathrm{C} 57 \mathrm{BL} / 10\left(\mathrm{H} 2^{\mathrm{b}}\right)$ hearts. On the day of transplantation, the recipients received either no treatment or single administration of aspirin (a cyclooxygenase 1 and 2 inhibitor) or the selective cyclooxygenase 2 inhibitor NS-398. Naive CBA mice (secondary recipients) underwent adoptive transfer of splenocytes from treated mice with long-surviving grafts (primary recipients) to determine whether regulatory cells developed after NS-398 treatment. Histologic, cell-proliferation, and cytokine studies were also performed.

Results: Untreated CBA mice rejected C57BL/10 cardiac grafts acutely (median survival time, 8 days). The majority of recipients given aspirin rejected their grafts within 20 days (median survival time, 11 days). In mice given NS-398, the majority of the grafts survived indefinitely (median survival time, $>100$ days). Secondary CBA recipients given $\mathrm{CD} 4^{+}$splenocytes from primary $\mathrm{CBA}$ recipients treated with NS-398 also had indefinite survival of C57BL/10 hearts (median survival time, $>60$ days). Graft acceptance and proliferative hyporesponsiveness were also confirmed by the histologic and cell-proliferation studies, respectively. Production of interleukin 4 and 10 from splenocytes of the recipients treated with NS-398 were significantly higher than that from untreated recipients.

Conclusions: In our model administration of cyclooxygenase 2 inhibitor induced indefinite survival of fully mismatched cardiac grafts and generated $\mathrm{CD} 4^{+}$regulatory cells. Cyclooxygenase 2 inhibitor could warrant consideration for use as an immunomodulating agent in clinical transplantation.

$\mathrm{T}$ Transplantation has become an accepted treatment for patients with end-stage organ failure. However, clinical success of organ transplantation has been achieved through the use of nonspecific immunosuppressive drugs to inhibit immune responses. These drugs generally need to be given for the life of the transplant and have many potential direct side effects, as well as increased risk of life-threatening complications, such as cardiovascular disease, infections, and malignancies. ${ }^{1}$

Prostaglandins (PGs), which are bioactive substances synthesized from arachidonic acids, are lipid inflammatory mediators that play central roles in modulating the immune response by means of complex interactions with leukocytes and parenchymal cells in inflamed organs. ${ }^{2}$ Cyclooxygenase (COX) is a key enzyme for 
synthesis of PGs and has at least 2 isoforms. The constitutive isoform, COX-1, exists in nearly all types of cells at a constant level and provides PGs in the gastric mucosa to maintain integrity of the mucosal epithelium and thromboxane $A_{2}$ in platelets to mediate hemostasis by means of platelet aggregation. In contrast, the COX-2 isoform is normally absent from cells but is induced dramatically by cytokines, tumor promoters, and mitogens on stimulation, especially in cells in the immune system, demonstrating that COX-2 can be involved in PG formation in inflammatory processes.

Highly selective COX-2 inhibitors should produce anti-inflammatory activity while eliminating the principal side effects associated with use of nonsteroidal antiinflammatory agents. ${ }^{3}$ Some studies have shown that COX-2 inhibitors might have other important therapeutic effects, such as preventing the development or progression of colorectal cancer ${ }^{4,5}$ and slowing cognitive decline in Alzheimer's disease. ${ }^{6}$ One transplantation investigation found that administration of $\mathrm{PGE}_{2}$ induced modest prolongation of rat cardiac allografts. ${ }^{7}$ On the other hand, treatment with aspirin, a COX-1 and COX-2 inhibitor, induced moderate prolongation of survival of cardiac allografts in rats. ${ }^{8}$ Moreover, COX-2 has been shown to be important in allograft rejection in both experimental and clinical transplantation. In a rat model of cardiac transplantation, COX-2 expression was significantly higher in allografts than in syngeneic grafts. ${ }^{9}$ Examinations of COX-2 expression in biopsy specimens from transplanted kidneys in human subjects found upregulation of COX-2 in allografts being rejected. ${ }^{10}$

In this study we investigated the effects of selective inhibition of COX-2 on graft survival in a murine model of cardiac transplantation. We used the compound $\mathrm{N}-(2-$ cyclohexyl-4-nitrophenyl) methane sulfonamide (NS-398), which specifically inhibits COX-2 activity without affecting COX $-1{ }^{11,12}$ We found that a single dose of NS-398 given on the day of transplantation induced indefinite survival of fully mismatched cardiac allografts and generated $\mathrm{CD}^{+}{ }^{+}$regulatory cells. Selective inhibition of COX-2 is widely used clinically for postoperative treatment of inflammatory processes, and our results suggest that COX-2 inhibitors also have the potential to be used as immunomodulatory agents to prevent rejection of allografts and drug-related toxicity of general immunosuppressants in patients.

\section{Materials and Methods}

\section{Animals and Transplantation}

Male C57BL/10 $\left(\mathrm{H} 2^{\mathrm{b}}\right), \mathrm{CBA}\left(\mathrm{H} 2^{\mathrm{k}}\right)$, and BALB/c $\left(\mathrm{H} 2^{\mathrm{d}}\right)$ mice were purchased from Sankyo Ltd (Tokyo, Japan), housed in conventional facilities at the Biomedical Services Unit of Teikyo University, and used in this study when 8 to 12 weeks old in accordance with the guidelines of the Animal Use and Care Committee of
Teikyo University. All transplantation procedures were performed with the mice after achievement of general anesthesia. Fully vascularized heterotopic hearts from C57BL/10 donors were transplanted into CBA recipients by using microsurgical techniques. ${ }^{13}$ Postoperatively, graft function was assessed by palpating the heart for evidence of contraction. Rejection was defined as complete cessation of contraction and confirmed by means of direct visualization and histologic examination of the graft. In some experiments, full-thickness skin grafts (approximately $1 \mathrm{~cm}^{2}$ ) were transplanted on the dorsal thorax of recipient mice and secured with an adhesive bandage for 7 days. Rejection was defined as the complete loss of viable epidermal graft tissue.

\section{Experiment 1: Allograft Survival in NS-398-treated Recipients}

On the day of transplantation, recipient mice were given either no drug treatment or a subcutaneous injection of one 20-mg dose of aspirin (a COX-1 and COX-2 inhibitor), dimethyl sulfoxide (DMSO; vehicle alone), or various doses of NS-398 (Cayman Chemical, Ann Arbor, Mich). Before administration, the NS-398 was dissolved in DMSO and diluted with phosphate-buffered saline in a 2:3 solution of DMSO/phosphate-buffered saline $(\mathrm{pH}$ 7.2).

\section{Histologic Studies of Harvested Grafts}

Cardiac grafts transplanted into untreated mice and mice given NS-398 were removed 7 and 100 days after transplantation and studied histologically. The specimens were immersion fixed in 5\% neutral buffered formalin and embedded in paraffin by using routine procedures. Paraffin sections $(4-\mu \mathrm{m}$ thick) were cut, mounted on sialine-coated slides, and stained with hematoxylin and eosin. Graft histology was assessed by using the International Society for Heart Transplantation Standardized Grading System, ${ }^{14}$ and transplant vasculopathy was assessed by scoring Elastica van Gieson-stained arteries as follows: less than 5\% occlusion, grade 0 ; greater than $5 \%$ to $20 \%$ occlusion, grade 1 ; greater than $20 \%$ to $40 \%$ occlusion, grade 2 ; greater than $40 \%$ to $60 \%$ occlusion, grade 3 ; greater than $60 \%$ to $80 \%$ occlusion, grade 4 ; and greater than $80 \%$ to $100 \%$ occlusion, grade $5 .{ }^{15}$

\section{Experiment 2: Adoptive Transfer Studies}

Adoptive transfer studies were conducted to determine whether regulatory cells were generated after treatment with NS-398. One hundred days after CBA recipients (primary recipients) received transplantation of C57BL/10 cardiac allograft with administration of NS-398, splenocytes $\left(5 \times 10^{7}\right)$ from the primary recipients with functioning allografts were adoptively transferred into naive CBA mice (secondary recipients). The secondary recipients underwent transplantation of C57BL/10 hearts immediately after the adoptive transfer. In some experiments, $\mathrm{CD} 4^{+}$cells were purified from the spleen in the primary recipients by means of positive selection with MACS CD4 Microbeads (Miltenyi Biotec Inc, Auborn, Calif; purity, $>98 \%$ ), and $2 \times 10^{7}$ of the $\mathrm{CD}^{+}$cells were adoptively transferred into naive secondary recipients that received transplantation of C57BL/10 hearts immediately afterward. 
TABLE 1. Survival of C57BL/10 cardiac grafts in treated CBA recipients

\begin{tabular}{|c|c|c|c|c|}
\hline Group & Treatment* & Graft survival (d) & MST (d) & $P$ valuet \\
\hline 1 & None & $5,7,7,8,9,9,9$ & 8 & \\
\hline 2 & DMSO & $7,7,7,10,11$ & 7 & NS vs 1 \\
\hline 3 & Aspirin $(20$ mg/kg) & $7,8,9,11,12,14,22$ & 11 & NS vs 1 \\
\hline 4 & NS-398 $(20 \mathrm{mg} / \mathrm{kg})$ & $40,54,54,55,65,79,94,94,100<\times 18$ & $100<$ & $<.0001$ vs 2 \\
\hline 5 & NS-398 (2 mg/kg) & $11,11,18,22,22$ & 18 & $<.05$ vs 2 \\
\hline 6 & NS-398 $(0.2 \mathrm{mg} / \mathrm{kg})$ & $6,8,8,8,22$ & 8 & \\
\hline 7 & NS-398 $(200 \mathrm{mg} / \mathrm{kg})$ & $1, \mp 1, \ddagger 1, \ddagger 3,3,3,4,4$ & 3 & \\
\hline
\end{tabular}

MST, Median survival time; DMSO, dimethyl sulfoxide (control vehicle); NS, not significant; vs 1, versus group 1; vs 2, versus group 2. *CBA recipients received transplantation of C57BL/10 hearts with a single administration of NS-398 or control substances (aspirin or dimethyl sulfoxide). $\dagger$ Mann-Whitney $U$ test. $\ddagger$ Recipients died with beating cardiac grafts.

\section{Experiment 3: Cell-proliferation, Cytokine, and Immunohistochemistry Studies}

In mixed leukocyte culture studies the responder cells were splenocytes from naive CBA mice or from untreated or NS-398-treated CBA mice that had undergone transplantation of a C57BL/10 heart 7 days earlier. Stimulator cells were C57BL/10 (allogeneic) or CBA (syngeneic) splenocytes treated with $100 \mu \mathrm{g} / \mathrm{mL}$ mitomycin $\mathrm{C}$ (Kyowa Hakko, Osaka, Japan) for 30 minutes at $37^{\circ} \mathrm{C}$. The responder cells $\left(0.25 \times 10^{6}\right)$ were cocultured with the stimulator cells $\left(1 \times 10^{6}\right)$ in complete medium in a humidified $5 \%$ $\mathrm{CO}_{2}$ atmosphere (CH-16M; Hitachi, Tokyo, Japan) at $37^{\circ} \mathrm{C}$ in 96-well, flat-bottomed, tissue-culture plates (Iwaki Scitech Division, Tokyo, Japan) for 3 to 6 days. ${ }^{16}$ Proliferation was assessed by using an enzyme-linked immunosorbent assay for bromodeoxyuridine incorporation (Biotrak, version 2; Amersham, Little Chalfont, United Kingdom), ${ }^{16,17}$ according to the manufacturer's instructions.

An enzyme-linked immunosorbent assay was also performed to assess levels of interleukin (IL) 2, IL-4, IL-10, and interferon (IFN)- $\gamma$ in the supernatant of the mixed leukocyte culture on day 4. The capture monoclonal antibody (mAb; JES5-2A5), detection mAb (JES5-16E3), and recombinant standard for IL-10 were from BD PharMingen (San Diego, Calif). The capture and detection mAbs for IL-2 (JES6-1A12 and JES6-5H4, respectively), IL-4 (BVD-1D11 and BVD-24G2, respectively), and IFN- $\gamma$ (R4-6A2 and XMG1.2, respectively) were from Caltag Laboratories (Burlingame, Calif). Recombinant standards for IL-2, IL-4, and IFN- $\gamma$ were from PeproTech (London, United Kingdom).

In the immunohistochemistry studies immunolabeling was performed on 4- $\mu \mathrm{m}$-thick, paraffin-embedded coronal sections of cardiac allografts fixed in Bouin solution (Medical Chemical Corp, Torrance, Calif). After deparaffinization, endogenous peroxidase activity was quenched with $0.3 \% \mathrm{H}_{2} \mathrm{O}_{2}$-methanol for 20 minutes. Nonspecific binding of the antibody was blocked with the NonSpecific Staining Blocking Reagent (DakoCytomation Co. Ltd., Kyoto, Japan) for 10 minutes, followed by incubation with polyclonal rabbit anti-COX-2 antibody (Cayman) at room temperature for 1 hour. Thereafter, sections were incubated for 30 minutes at room temperature with the secondary biotinylated goat anti-rabbit immunoglobulin G antibody (Vector Labs, Burlingame, Calif). After washing with $0.05 \mathrm{M}$ Tris- $\mathrm{HCl}$, the sections were incubated with avidin-biotin-peroxidase complexes (Vector Labs) for 30 minutes at room temperature, and peroxidase activity was demon- strated with 3,3' diaminobenzidine. Rabbit immunoglobulin $\mathrm{G}$ was used as a negative control. Sections were counterstained with Meyer's hematoxylin.

\section{Statistical Analysis}

The allograft survival in 2 groups was compared by using MannWhitney $U$ tests (StatView SE + Graphics; Abacus Concepts, Cary, NC). In the cell-proliferation and cytokine studies, 2 groups were compared by using unpaired Student $t$ tests (StatView SE + Graphics).

\section{Results}

\section{Experiment 1: NS-398-induced Prolongation of} Allograft Survival in a Dose-dependent Manner CBA mice given either no treatment or DMSO (control vehicle) at transplantation rejected C57BL/10 cardiac grafts acutely (median survival time [MST], 8 and 7 days, respectively; Table 1, group 1 and 2). Mice given aspirin had slightly prolonged allograft survival (MST, 11 days; $\mathrm{n}=7$; Table 1, group 3). The majority of the mice given $20 \mathrm{mg} / \mathrm{kg}$ NS-398 had indefinite graft survival (MST, $<100$ days; $\mathrm{n}$ $=26$; Table 1 , group 4; $P<.0001$ vs DMSO [control vehicle]). On the other hand, when the recipients were treated with $2 \mathrm{mg} / \mathrm{kg}$ NS-398, they had only modest prolongation of allograft survival (MST, 18 days; $n=5$; Table 1 , group 5). When treated with $0.2 \mathrm{mg} / \mathrm{kg}$, prolongation of allograft survival was not observed (MST, 8 days; Table 1, group 6). When treated with $200 \mathrm{mg} / \mathrm{kg}$ NS-398, the allografts were also rejected acutely, with an MST 3 days, because $200 \mathrm{mg} / \mathrm{kg} \mathrm{NS}-398$ might be toxic to the recipients and allografts (Table 1, group 7). Three other recipients in the group receiving $200 \mathrm{mg} / \mathrm{kg}$ NS-398 died 1 day after transplantation bearing beating cardiac grafts. These data suggest that a single dose of NS-398 induced unresponsiveness to fully mismatched cardiac allograft in a dosedependent manner. Histologic examinations of cardiac grafts harvested 100 days after transplantation (Figure 1, A; grade 0-1A) showed that the C57BL/10 grafts in CBA mice treated with NS-398 were similar to syngeneic grafts (Figure $1, B)$, with only a few infiltrating leukocytes and no 

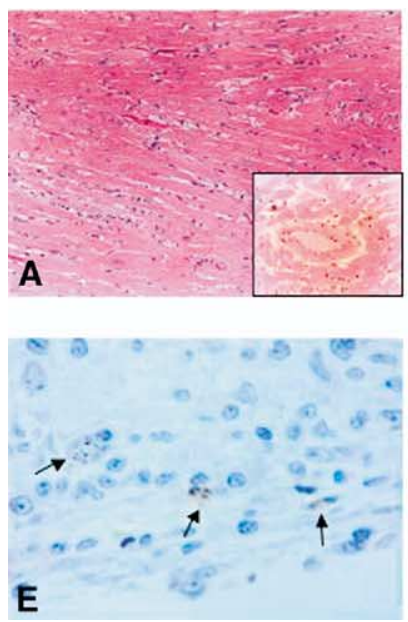
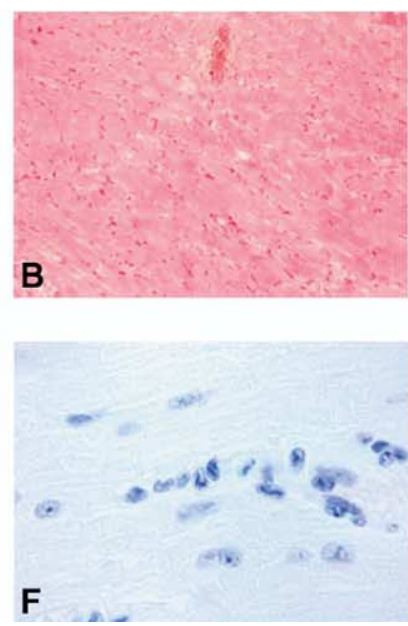
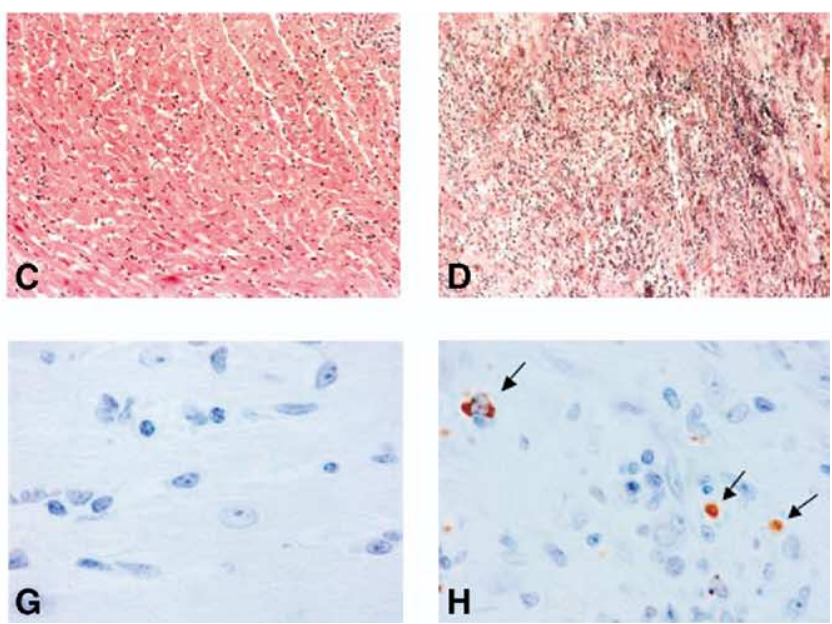

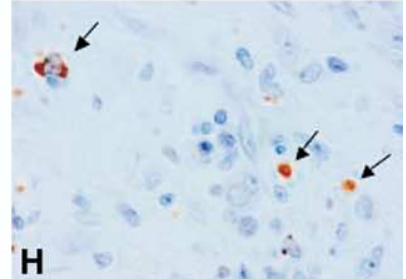

Figure 1. Histologic studies of harvested cardiac grafts, with hematoxylin and eosin staining (A-D) and COX-2 immunostaining (E-H). A, C57BL/10 allograft obtained 100 days after transplantation from a CBA recipient given 20 $\mathrm{mg} / \mathrm{kg}$ NS-398 the day of transplantation. B, CBA graft (syngeneic graft) harvested from a CBA recipient 100 days after transplantation. C, C57BL/10 allograft harvested from an NS-398-treated CBA recipient 7 days after transplantation. D, C57BL/10 allograft harvested from an untreated CBA recipient 7 days after transplantation (showing for positive control). (Hematoxylin and eosin stain; original magnification $50 \times$ and $100 \times$ [inset].) Immunohistochemistry studies of harvested cardiac allografts for cyclooxygenase 2 staining. $E$, C57BL/10 allograft harvested from an untreated CBA recipient 7 days after transplantation. F, C57BL/10 cardiac graft obtained immediately after harvesting from donor C57BL/10 mice. G, C57BL/10 allograft harvested from an NS-398-treated CBA recipient 14 days after transplantation. $\mathrm{H}, \mathrm{C57BL} / 10$ allograft harvested from an NS-398-treated CBA recipient 30 days after transplantation (cyclooxygenase-positive leukocytes [arrows $\rrbracket$. (Original magnification $300 \times$.)

evidence of chronic rejection (transplant vasculopathy; grade 0). Interestingly, at 7 days after transplantation (Figure 1, $C$; grade 0-1B), many leukocytes were observed infiltrating the allografts in mice given NS-398, indicating that the anti-inflammatory effect of the agent was not completely operative in our model.

To determine whether the unresponsiveness induced in the CBA recipients with $20 \mathrm{mg} / \mathrm{kg}$ NS-398 was donor specific, we conducted a second challenge of skin grafting to the recipients with long-surviving cardiac allografts after NS-398 treatment. One hundred days after transplantation, these mice were given donor-specific (C57BL/10) or thirdparty $(B A L B / c)$ skin grafts. The donor-specific skin grafts had significantly longer survivals than the third-party skin grafts (MST, 14 and 11 days, respectively; $\mathrm{n}=5 ; P<.05$, data not shown), indicating that the unresponsiveness might be donor specific. The donor specificity was also confirmed by using the mixed leukocyte culture assay (data not shown).

\section{Experiment 2: NS-398 Treatment Generated}

\section{Regulatory Cells}

In the adoptive transfer studies secondary CBA recipients given adoptive transfer of splenocytes from the primary recipients with $20 \mathrm{mg} / \mathrm{kg}$ NS-398 had prolonged survival of
C57BL/10 hearts (Figure 2, A; MST, 62 days; $\mathrm{n}=5$ ) but rejected third-party $(\mathrm{BALB} / \mathrm{c})$ allografts acutely (survival time, $8,12,14,17$, and 38 days; MST, 14 days). In contrast, secondary CBA recipients given adoptive transfer of splenocytes from naive CBA mice (control group) rejected C57BL/10 hearts acutely (MST, 9 days; $\mathrm{n}=7$ ). When $\mathrm{CD}^{+}$ cells were purified from the primary recipients with NS-398 treatment and were adoptively transferred into naive secondary recipients, all allografts in the secondary recipients survived indefinitely (Figure 2, $B ; \mathrm{n}=5 ; P<.01$ compared with that in the control group). Adoptive transfer of $\mathrm{CD}^{+}$cells that were purified from naive CBA mice did not induce graft prolongation (MST, 12 days; $n=5$ ). These data suggest that NS-398 treatment induced $\mathrm{CD}^{+}{ }^{+}$regulatory cells.

Experiment 3: Cell-proliferation, Cytokine, and Immunohistochemistry Studies

Maximum proliferation of naive CBA splenocytes (responder cells) against C57BL/10 splenocytes (stimulator cells) treated with mitomycin $\mathrm{C}$ occurred on day 4 of the mixed leukocyte culture. Proliferation of splenocytes from CBA mice given NS-398 was significantly reduced compared with that of splenocytes from untreated mice or naive CBA mice (Figure 3, A). 


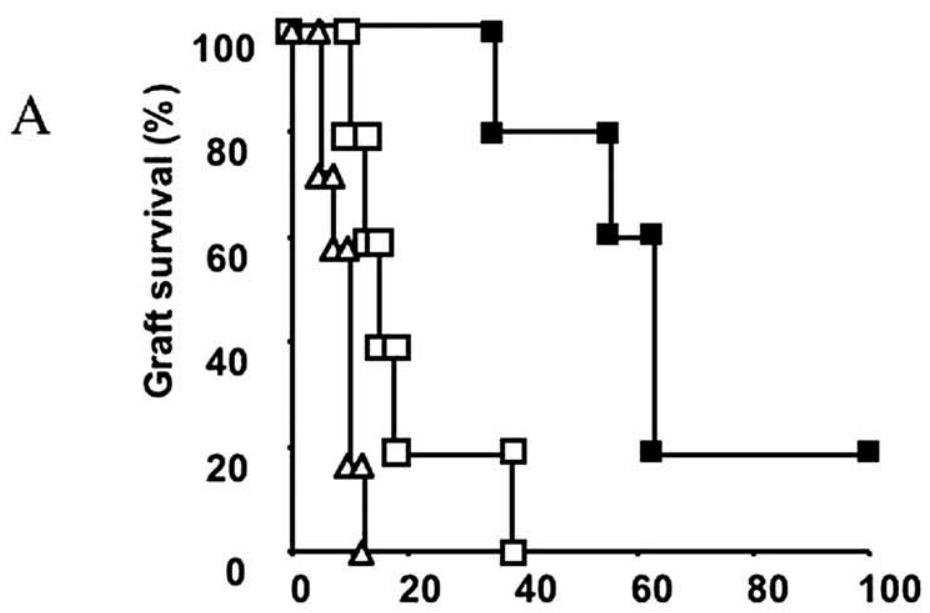

Days after adoptive transfer of whole splenocytes

Adoptive transfer from; graft n MST (days)

$\left.\begin{array}{ccllc}- & \text { NS-398 treated recipients } & \text { C57BL/10 } & 5 & 62 \\ -\square- & \text { NS-398 treated recipients } & \text { BALB/C } & 5 & 14\end{array}\right] \#$ \#

B

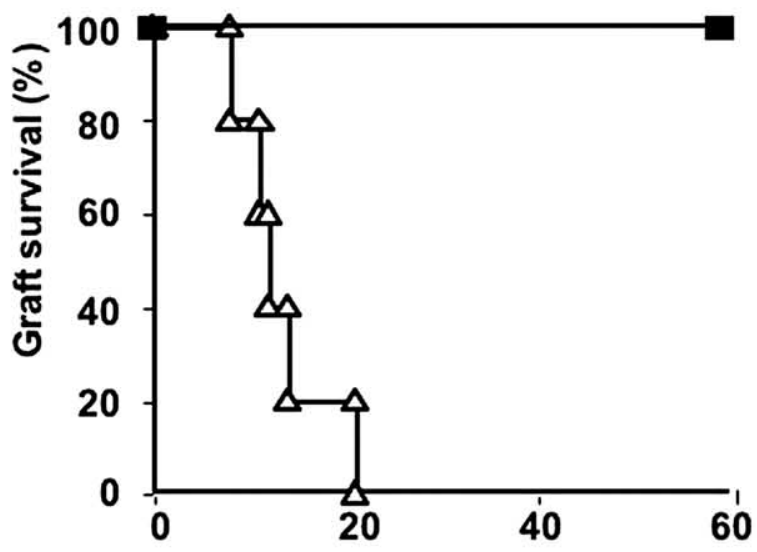

Days after adoptive transfer of $\mathrm{CD}^{+}$cells

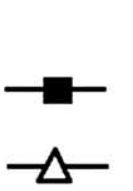

$$
\text { Adoptive transfer from; }
$$

NS-398 treated recipients

Naïve CBA mice n

MST (days)

5

5

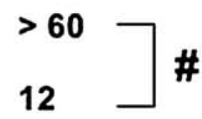

Figure 2. A, Graft survival after adoptive transfer of splenocytes. CBA mice (primary recipients) were treated with $20 \mathrm{mg} / \mathrm{kg} \mathrm{NS}-398$ and underwent transplantation of C57BL/10 cardiac grafts the same day. One hundred days later, splenocytes $\left(5 \times 10^{7}\right)$ from the primary recipients with functioning allografts were adoptively transferred into naive CBA mice (secondary recipients) that were then given C57BL/10 cardiac grafts. Secondary recipients in the control group underwent adoptive transfer of splenocytes from naive CBA mice (\#P<.01 between the 2 groups). B, Graft survival after adoptive transfer of $\mathrm{CD4}^{+}$cells. CBA mice (primary recipients) were treated with $20 \mathrm{mg} / \mathrm{kg} \mathrm{NS}-398$ and underwent transplantation of C57BL/10 cardiac grafts the same day. One hundred days later, CD4 ${ }^{+}$cells were purified from the spleen in the primary recipients with functioning allografts by using positive selection with MACS CD4 Microbeads, and $2 \times 10^{7} \mathrm{CD}^{+}$cells were adoptively transferred into naive secondary recipients that received transplantation of C57BL/10 hearts immediately afterward. 

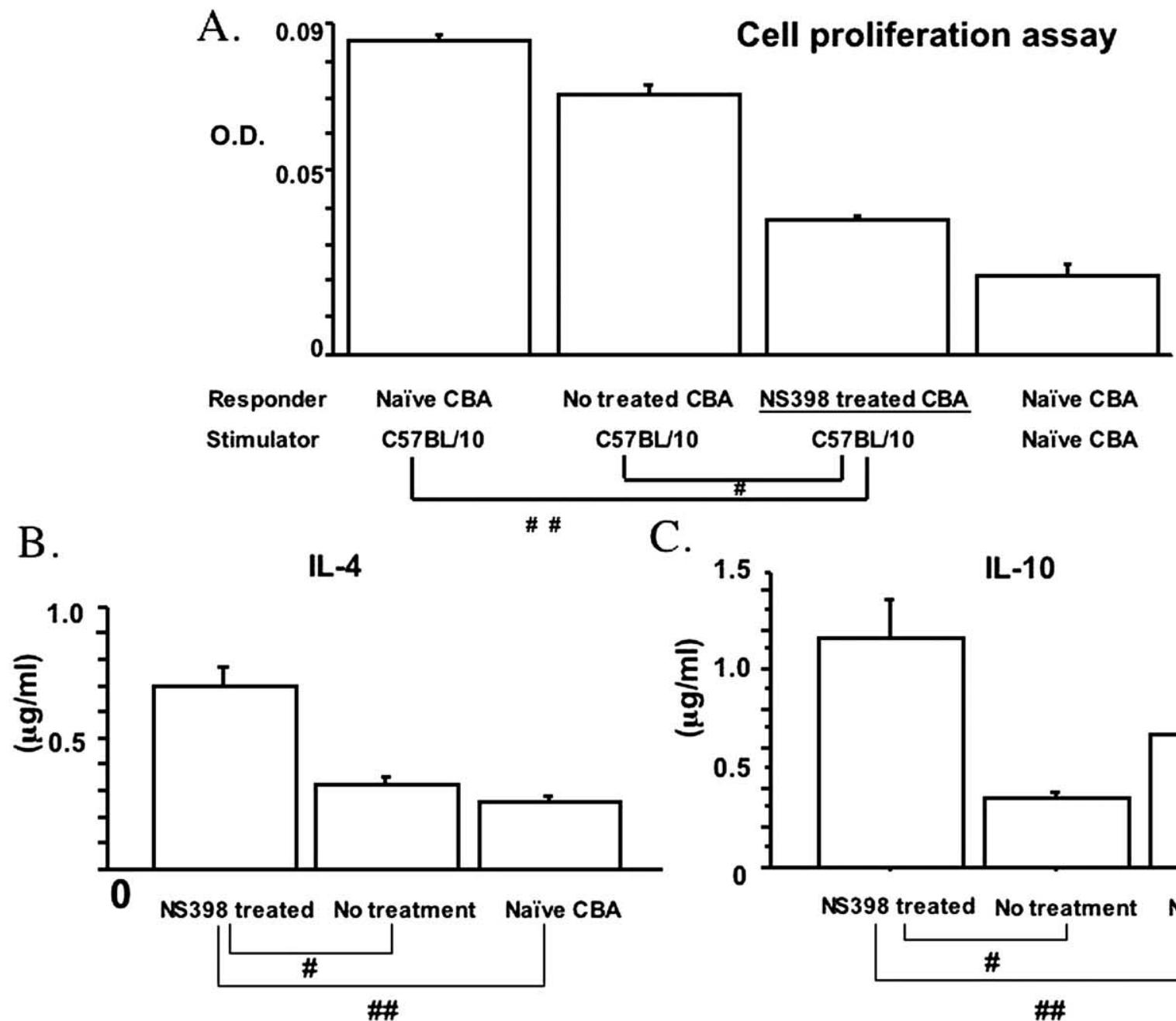

Figure 3. A, Results of cell-proliferation assay in mixed leukocyte culture. Untreated CBA mice and mice treated with NS-398 $(20 \mathrm{mg} / \mathrm{kg})$ were given cardiac grafts from C57BL/10 mice. Seven days later, splenocytes $\left(0.25 \times 10^{6}\right.$ cells) from the CBA mice (responder cells) were cocultured with splenocytes from either C57BL/10 mice (stimulator cells; $1 \times 10^{6}$ cells) (\#P<.01 between 2 groups). B and C, Levels of cytokines in the mixed leukocyte culture. Untreated CBA mice and mice treated with NS-398 $(20 \mathrm{mg} / \mathrm{kg})$ were given cardiac grafts from C57BL/10 mice. Seven days later, splenocytes $\left(0.25 \times 10^{6}\right.$ cells) from the CBA mice (responder cells) were cocultured with splenocytes from either C57BL/10 mice (stimulator cells; $1 \times 10^{6}$ cells) for 4 days. Levels of interleukin 4 (IL-4; B), interleukin 10 (IL-10; C), interleukin 2, and interferon $\gamma$ in the mixed leukocyte culture were assessed by using enzyme-linked immunosorbent assays. There were no differences between groups in interleukin 2 or interferon $\gamma$ levels (data not shown; \#P<.01 and \#P $<.05$ between 2 groups).

Levels of IL-4 (Figure 3, B) and IL-10 (Figure 3,C) in splenocytes from mice treated with NS-398 were significantly higher than those in splenocytes from untreated mice or in syngeneic splenocytes. There were no differences between groups in levels of IL-2 or IFN- $\gamma$ (data not shown).

Results of the immunohistochemistry studies are shown in Figure 1. COX-2 expression was observed mainly on leukocytes, such as polymorphonuclear leukocytes and monocytes.
In untreated mice that underwent transplantation of allograft, COX-2 expression in their cardiac grafts was already upregulated on day 7 after transplantation (Figure 1,E), whereas no COX-2 expression was observed in hearts from naive mice (Figure 1, F). In mice given NS-398 (20 mg/kg), COX-2 expression in the allografts was not detected from day 7 through day 14 after transplantation (Figure 1, G). On day 30 after transplantation, however, COX-2 expression had returned 
to levels similar to those observed in allografts in untreated mice (Figure 1, $H$ ). These data suggest that the anti-inflammatory effect (suppression of COX-2) of NS-398 was temporary, even though the hyporesponsiveness induced by the treatment continued until day 100 after transplantation.

\section{Discussion}

In this study treatment with a single dose of a selective COX-2 inhibitor, NS-398, induced indefinite survival of fully allogeneic grafts in a murine model of cardiac transplantation. In the majority of mice given the optimal dose of this agent $(20 \mathrm{mg} / \mathrm{kg})$, no evidence of either acute or chronic rejection was observed. Treatment with NS-398 also resulted in generation of regulatory cells by 100 days after transplantation, and these cells had suppressive activity in a mixed leukocyte culture. Furthermore, splenocytes from mice given NS-398 had increased levels of IL-4 and IL-10 in a mixed leukocyte culture. $\mathrm{CD} 4^{+}$cells were one of the regulatory populations.

Recently, Ma and associates ${ }^{18}$ found that daily administration of another COX-2 inhibitor reduced leukocyte infiltration and apoptosis of cardiomyocytes by nitric oxide in a rat model of cardiac transplantation, although survival of the allografts was only slightly prolonged. On the other hand, our study showed that a single administration of NS-398 on the day of transplantation induced indefinite survival of allografts in the majority of the recipients, suggesting that other mechanisms contribute to the long-term acceptance of the allograft in our study.

The mechanisms of allograft unresponsiveness have been classified as deletion, anergy, and immune regulation. ${ }^{19}$ In our study, when the secondary naive CBA recipients were adoptively transferred with $5 \times 10^{7}$ splenocytes from the CBA recipients with functioning C57BL/10 allografts after NS-398 treatment, the secondary recipients accepted C57BL/10 cardiac allografts. Furthermore, all grafts survived indefinitely in the secondary recipients, with adoptive transfer of $\mathrm{CD}^{+}$cells from the primary recipients with NS-398 treatment. These data demonstrated that $\mathrm{CD}^{+}{ }^{+}$regulatory cells were generated after NS-398 treatment and that immune regulation might be involved in one of the mechanisms to permit long-term acceptance of the allograft by NS-398 treatment. However, donor-specific skin grafts as a second challenge were eventually rejected, suggesting that NS-398 treatment did not induce transplantation tolerance. One possibility is that the number, function, or both of the regulatory cells might not be sufficient for inducing indefinite survival of second challenge of the donor-specific skin grafts.

On 100 days after transplantation in our study, the histologic findings in the cardiac allografts in the mice given NS-398 were similar to those in syngeneic grafts. However, our immunohistochemistry assessments indicated that the anti-inflammatory effect (ie, suppression of COX-2) of a single dose of NS-398 on the day of transplantation was temporary because $\mathrm{COX}-2^{+}$cells were detected infiltrating into the allograft around 30 days after transplantation. These data might indicate that the hyporesponsiveness induced by NS-398 have resulted from immunomodulatory, rather than anti-inflammatory, activity, leading to the subsequently inducing regulatory cells, although NS-398 might have other capacities as an immunosuppressive agent that are unrelated to $\mathrm{COX}-2$ inhibition.

In some previous studies, aspirin or a COX-2 inhibitor was found to regulate the maturation of murine $\mathrm{e}^{20}$ and hu$\operatorname{man}^{21}$ dendritic cells, and aspirin administration resulted in an impairment of the ability of dendritic cells to stimulate $\mathrm{T}$-cell responses in vivo. In our study splenocytes from mice given NS-398 produced higher levels of both IL-4 and IL-10 in a mixed leukocyte culture 7 days after transplantation of cardiac allografts than those produced by splenocytes from untreated transplant recipients. IL-10 is a principal regulatory cytokine in the maturation of dendritic cells. ${ }^{22}$ Moreover, under some circumstances, IL-10, IL-4, or both were observed to be required for the induction or function of regulatory cells in autoimmunity ${ }^{23,24}$ or transplantation ${ }^{25,26}$ models. These findings and the results of our adoptive transfer studies indicate that treatment with NS398 might inhibit immunologic responses against allografts by means of IL-4 and IL-10, presumably through inhibition of dendritic cell maturation in the induction phase of hyporesponsiveness and through generation of regulatory cells in the maintenance phase.

In summary, we found that the COX-2 inhibitor NS-398 had an immunomodulatory effect that induced indefinite survival of cardiac allografts, as well as having an antiinflammatory effect. We also showed that treatment with NS-398 generated $\mathrm{CD}^{+}{ }^{+}$regulatory cells in our model. In patients, nonsteroidal anti-inflammatory agents, including COX-2 inhibitors, are commonly used for pain control after surgical intervention. Therefore NS-398 might have the potential to be clinically useful after organ transplantation as adjuvant therapy given with conventional nonspecific immunosuppressive agents to allow a reduction in the total dose of those agents, thereby possibly preventing such side effects as direct drug toxicity, infection, and malignant disease. Testing of this strategy in a large-animal model is warranted.

We thank Ryuichi Taki, Mitsubishi Kagaku Bio-Clinical Laboratories, Inc, Tokyo, Japan, for technical assistance in immunohistochemical and histologic studies.

\section{References}

1. Denton MD, Magee CC, Sayegh MH. Immunosuppressive strategies in transplantation. Lancet. 1999;353:1083-91.

2. Vane JR, Bakhle YS, Botting RM. Cyclooxygenases 1 and 2. Annu Rev Pharmacol Toxicol. 1998;38:97-120. 
3. Hawkey CJ. COX-2 inhibitors. Lancet. 1999;353:307-14.

4. Kawamori T, Rao CV, Seibert K, Reddy BS. Chemopreventive activity of celecoxib, a specific cyclooxygenase-2 inhibitor, against colon carcinogenesis. Cancer Res. 1998;58:409-12.

5. Smalley W, Ray WA, Daugherty J, Griffin MR. Use of nonsteroidal anti-inflammatory drugs and incidence of colorectal cancer: a population-based study. Arch Intern Med. 1999;159:161-6.

6. McGeer PL, Schulzer M, McGeer EG. Arthritis and anti-inflammatory agents as possible protective factors for Alzheimer's disease: a review of 17 epidemiologic studies. Neurology. 1996;47:425-32.

7. Stone CD, Rosengard BR, Boorstein SM, Robbins RC, Hennein HA, Clark RE. Prostaglandin E2 inhibits in vitro and in vivo lymphocyte responses in allogeneic transplantation. Ann Thorac Surg. 1990;49: 927-31.

8. Shaw JF. Prolongation of rat cardiac allograft survival by treatment with prostacyclin or aspirin during acute rejection. Transplantation. 1983;35:526-9.

9. Yang X, Ma N, Szabolcs MJ, Zhong J, Athan E, Sciacca RR, et al. Upregulation of COX-2 during cardiac allograft rejection. Circulation. 2000;101:430-8.

10. Hausknecht B, Voelk1 S, Riess R, Gauer S, Goppelt-Struebe M. Expression of cyclooxygenase-2 in biopsies obtained from human transplanted kidneys undergoing rejection. Transplantation. 2003;76: 109-14.

11. Futaki N, Arai I, Hamasaka Y, Takahashi S, Higuchi S, Otomo S. Selective inhibition of NS-398 on prostanoid production in inflamed tissue in rat carrageenan-air-pouch inflammation. J Pharm Pharmacol. 1993;45:753-5.

12. Futaki N, Takahashi S, Yokoyama M, Arai I, Higuchi S, Otomo S. NS-398, a new anti-inflammatory agent, selectively inhibits prostaglandin G/H synthase/cyclooxygenase (COX-2) activity in vitro. Prostaglandins. 1994;47:55-9.

13. Niimi M. The technique for heterotopic cardiac transplantation in mice: experience of 3000 operations by one surgeon. J Heart Lung Transplant. 2001;20:1123-8.

14. Billingham ME, Cary NR, Hammond ME, Kemnitz J, Marboe C, McCallister HA, et al. A working formulation for the standardization of nomenclature in the diagnosis of heart and lung rejection: Heart
Rejection Study Group. The International Society for Heart Transplantation. J Heart Transplant. 1990;9:587-93.

15. Hancock WW, Buelow R, Sayegh MH, Turka LA. Antibody-induced transplant arteriosclerosis is prevented by graft expression of antioxidant and anti-apoptotic genes. Nat Med. 1998;4:1392-6.

16. Akiyama Y, Shirasugi N, Uchida N, Matsumoto K, Kitajima M, Bashuda $\mathrm{H}$, et al. B7/CTLA4 pathway is essential for generating regulatory cells after intratracheal delivery of alloantigen in mice. Transplantation. 2002;74:732-8.

17. Perros P, Weightman DR. Measurement of cell proliferation by enzyme-linked immunosorbent assay (ELISA) using a monoclonal antibody to bromodeoxyuridine. Cell Prolif. 1991;24:517-23.

18. Ma N, Szabolcs MJ, Sun J, Albala A, Sciacca RR, Zhong M, et al. The effect of selective inhibition of cyclooxygenase (COX)-2 on acute cardiac allograft rejection. Transplantation. 2002;74:1528-34.

19. Wood KJ, Jones ND, Bushell AR, Morris PJ. Alloantigen-induced specific immunological unresponsiveness. Philos Trans $R$ Soc Lond B Biol Sci. 2001;356:665-80.

20. Hackstein H, Morelli AE, Larregina AT, Ganster RW, Papworth GD, Logar AJ, et al. Aspirin inhibits in vitro maturation and in vivo immunostimulatory function of murine myeloid dendritic cells. $J \mathrm{Im}$ munol. 2001;166:7053-62.

21. Whittaker DS, Bahjat KS, Moldawer LL, Clare-Salzler MJ. Autoregulation of human monocyte-derived dendritic cell maturation and IL-12 production by cyclooxygenase-2-mediated prostanoid production. J Immunol. 2000;165:4298-304.

22. Bell D, Young JW, Banchereau J. Dendritic cells. Adv Immunol. 1999;72:255-324.

23. Groux H, O'Garra A, Bigler M, Rouleau M, Antonenko S, de Vries JE, et al. A CD4+ T-cell subset inhibits antigen-specific T-cell responses and prevents colitis. Nature. 1997;389:737-42.

24. Faria AM, Weiner HL. Oral tolerance: mechanisms and therapeutic applications. Adv Immunol. 1999;73:153-264.

25. Bushell A, Niimi M, Morris PJ, Wood KJ. Evidence for immune regulation in the induction of transplantation tolerance: a conditional but limited role for IL-4. J Immunol. 1999;162:1359-66.

26. Hara M, Kingsley CI, Niimi M, Read S, Turvey SE, Bushell AR, et al. IL-10 is required for regulatory T cells to mediate tolerance to alloantigens in vivo. J Immunol. 2001;166:3789-96. 